\title{
Hypofractionation Radiotherapy vs. Conventional Fractionation for Breast Cancer: A Comparative Review of Toxicity
}

\author{
Ashraf Youssef ${ }^{1}$, Jason Stanford ${ }^{1}$ \\ 1. Radiation Oncology, Geisinger / Holy Spirit, Mechanicsburg, USA
}

Corresponding author: Ashraf Youssef, ashrafyoussef@yahoo.com

\begin{abstract}
The use of postoperative radiation therapy after breast-conserving surgery was longstanding standard practice. The treatment protocol used a standard fractionation of $50 \mathrm{~Gy}$ in 25 fractions plus a boost. Recently, the hypofractionation approach has gained support based on Canadian and English studies that claimed equal tumor control and similar toxicity to the standard protocol.
\end{abstract}

We conducted a review of the literature of hypofractionation studies and compared the reported toxicity with the general literature. We placed special emphasis on breast fibrosis after hypofractionation versus standard fractionation. We found a striking difference in the breast toxicity reported by the hypofractionation literature regarding breast fibrosis as compared to standard fractionation. Breast fibrosis should be explored further via additional studies and discussed with potential breast-conserving surgery patients.

Categories: Radiation Oncology, Oncology

Keywords: breast cancer, hypofractionated, standard fractionation, radiation therapy, breast fibrosis

\section{Introduction And Background}

Recently, the American Society of Radiation Oncology released a task force guideline recommending hypofractionated radiotherapy for all women of any age whether they had received chemotherapy or not [1]. Their evidence-based recommendations were supported by studies from Canada and the United Kingdom [26]. This study is a review of the scientific and radiobiological basis for the two treatment protocols (hypofractionation and standard fractionation) and an evaluation of the short-term and long-term toxicity reported.

Received 09/27/2018

Review began 10/05/2018 Review ended 10/23/2018 Published 10/29/2018

() Copyright 2018 Youssef et al. This is an open access article distributed under the terms of the Creative Commons Attribution License CC-BY 3.0 , which permits unrestricted use, distribution, and reproduction in any medium, provided the original author and source are credited.

\section{Review}

According to Hall, "laboratory data proved that fewer and large dose fractions result in more severe late reactions, even though the early reactions are matched by an appropriate adjustment in total dose" [7]. Hall also reports that if "a fractionated scheme is changed in clinical practice from many small doses to a few large fractions and the total dose is titrated to produce equal early effects, the treatment protocol involving a few large fractions results in more severe late effects" [7]. Fraction size, according to Hall, "is the dominant factor in determining late effects, the overall treatment time has little influence" [7].

We calculated the biological effective dose (BED) for both protocols using $\alpha / \beta$ of 3 Gy for late tissues and $\alpha / \beta$ of $10 \mathrm{~Gy}$ for early tissues.

In regards to the standard fractionation (50 Gy in 2-Gy fractions), the BED for late tissues was $83.3 \mathrm{~Gy}$ and 60 Gy for early tissues where:

$\mathrm{BED}=\mathrm{nd}(1+\mathrm{n} /(\alpha / \beta))$

Comparatively, for hypofractionation (41.6 Gy in 3.2 Gy per fraction), the BED for late tissues was 86 Gy and 55 Gy for early tissues.

Table 1 presents a comparative analysis of the BED for different dose protocols. 


\section{Cureus}

\begin{tabular}{|c|c|c|c|c|}
\hline \multirow[b]{2}{*}{ BED } & \multirow{2}{*}{$\begin{array}{l}\text { Standard } \\
50 \text { Gy in } 2\end{array}$} & \multicolumn{3}{|l|}{ Hypofractionation } \\
\hline & & 41.6 Gy in $3.2 \mathrm{Fx}$ & 39 Gy in 3 Gy & 42.56 Gy in 2.66 Gy \\
\hline Early $(\alpha / \beta=10)$ & 60 & 55 & 50.7 & 53.88 \\
\hline Late $(\alpha / \beta=3)$ & 83.3 & 86 & 78 & 80 \\
\hline \# of fractions & 25 & 13 & 13 & 16 \\
\hline Average time in days & 33 days & 17 & 17 & 22 \\
\hline
\end{tabular}

TABLE 1: Comparative analysis of the BED for the different dose protocols

BED: biological effective dose

The UK Standardization Breast Radiotherapy START Trial A and B found that breast appearance and breast hardness were the most common changes among the two groups but the results were similar (42.6\% for the $50 \mathrm{~Gy}$ in two fractions and $44.6 \%$ for the $41.6 \mathrm{~Gy}$ in $3.2 \mathrm{~Gy}$ per fraction or $39 \mathrm{~Gy}$ in 3 Gy per fraction) [2-3].

START Trial A showed no significant difference between the breast hardness caused by 50 Gy in 2-Gy fractions and $40 \mathrm{~Gy}$ in 15 fractions. The trial reported $38.2 \%$ of the breasts were "Harder" with hypofractionation versus $42.3 \%$ for standard fractionation.

Leong et al. found no added swelling to the arm using hypofractionation. The hypofractionation daily dose was $2.25 \mathrm{~Gy}$ to $2.5 \mathrm{~Gy}$ to a total of $45 \mathrm{~Gy}$ to $40 \mathrm{~Gy}$, respectively. The conventional fractionation ranged between $1.8 \mathrm{~Gy}$ and $2 \mathrm{~Gy}$ to a total dose of $45 \mathrm{~Gy}$ to $50.4 \mathrm{~Gy}$, respectively. Of 1,759 patients, 708 were evaluated (40\%). The two groups were not equal, 406 patients received hypofractionation, and 302 received conventional fractionation [8].

Whelan et al. reported no difference in toxicity between $50.0 \mathrm{~Gy}$ in 25 fractions over a period of 35 days and a dose of $42.5 \mathrm{~Gy}$ in 16 fractions. Grade two subcutaneous toxicity had tripled in 10 years as compared to the $30 \%$ increase for standard fractionation [4].

Yarnold et al. found that the probability of moderate/marked breast induration after 50 Gy in 2-Gy fractions was between $39 \mathrm{~Gy}$ in 13 fractions and $42.9 \mathrm{~Gy}$ in 13 fractions with fewer side effects for the 3.3-Gy fraction size [6].

Reddy et al. compared hypofractionation versus standard fractionation for 287 women treated from 2011 to 2017 (42.56 Gy in 16 fractions plus $10 \mathrm{~Gy}$ to $12.5 \mathrm{~Gy}$ in four to five fractions boost or $50 \mathrm{~Gy}$ in 25 fractions plus $10 \mathrm{~Gy}$ to $14 \mathrm{~Gy}$ in five to seven fractions). The cosmetic assessment was dependent on photographs and the patient's own assessment. There was no report of breast fibrosis. They reported similar or improved cosmetic outcomes with hypofractionation as compared to standard fractionation [9].

These studies showed a high rate of breast fibrosis with hypofractionation and a similarly high rate of breast fibrosis with standard fractionation.

Haviland reported more side effects with a fractionation schedule of 13 sessions at 3.3 Gy versus 50 sessions at $2 \mathrm{~Gy}$ or 39 sessions at $3 \mathrm{~Gy}$. There was a statistically significantly increased rate of physician-assessed shoulder stiffness in the 42.9-Gy schedule compared to the 50-Gy treatment in the START pilot (hazard ratio, $3.07 ; 95 \%$ confidence interval, 1.62 to $5.83, \mathrm{p}=0.001$ ). There was no such effect reported for the hypofractionated schedules in START-A and START-B [10]. Table 2 presents a comparison of the incidence of breast induration. 


\section{Cureus}

\begin{tabular}{|c|c|c|}
\hline \multirow[t]{2}{*}{ Study } & Hypofractionation & $\begin{array}{l}\text { Standard Fractionation } 50 \text { Gy ( } 2 \text { Gy x } 25 \\
\text { fractions) }\end{array}$ \\
\hline & \multicolumn{2}{|c|}{ Incidence of Breast Induration } \\
\hline \multicolumn{3}{|l|}{ START A [2] } \\
\hline 41.6 Gy (3.2 Gy x13 fractions) & $44.6 \%$ & $42.6 \%$ \\
\hline 39 Gy (3 Gy x 13 fractions) & $34.9 \%$ & $42.6 \%$ \\
\hline START B [3] 40 Gy (2.67 x 15 fractions) & $38.2 \%$ & $42.3 \%$ \\
\hline Whelan [5] 42.5 Gy (2.65 Gy x 16 tractions) 5 years Grade 2 & $3.8 \%$ & $5.2 \%$ \\
\hline 10 years Grade 2 & $9.4 \%$ & $6.8 \%$ \\
\hline $\begin{array}{l}\text { Yarnold [6] (overall induration) } 42.9 \text { Gy (3.3 Gy x } 13 \text { fractions); } 39 \text { Gy (3 Gy in } \\
13 \text { fractions) }\end{array}$ & $40.8 \% ; 20.4 \%$ & $28.6 \%$ \\
\hline
\end{tabular}

TABLE 2: Comparison of the incidence of breast induration

Xiaofeng et al. found that $50 \%$ to $60 \%$ of the patients had developed mild to moderate late breast fibrosis one year after hypofractionation radiation therapy ( $40 \mathrm{~Gy}$ plus simultaneous cavity boost to 48 Gy in 15 fractions) [11]. Yu et al. found 19\% subcutaneous fibrosis after hypofractionation, yet "good" or "excellent" cosmesis was reported in $94 \%$ of the cases [12]. According to Pezner, a "course of external beam radiation therapy to the whole breast to a dose of $50 \mathrm{~Gy}$ in 25 fractions without local boost yields cosmetic results with little if any palpable fibrosis, even after 12 years of follow-up" [13]. Bartelink et al. reported a 1.6\% incidence of breast fibrosis after 50 Gy regular fractionation and only 4.4\% after adding $16 \mathrm{~Gy}$ boost [14]. Murphy et al. reported only $8.4 \%$ breast fibrosis (273 patients of 3,186 ) after using standard fractionation followed by a boost of 10 to $16 \mathrm{~Gy}$. He concluded that breast fibrosis was related to large breast cup size and higher electron energy used for the boost [15]. Harris et al. reported breast fibrosis after 5000 cGy of breast radiation is rare. He also reported an increase in breast fibrosis after $6000 \mathrm{cGy}$ [16].

De La Rochefordiere et al. found that using a dose of more than $2 \mathrm{~Gy}$ per fraction is associated with worse cosmesis [17]. Clark et al. concluded that daily fractionation with a dose of $2.5 \mathrm{~Gy}$ leads to greater fibrosis and breast retraction [18]. There were many reports stating that radiation oncologists in the United States are reluctant to adopt the hypofractionation regimen [19].

\section{Conclusions}

There is some discrepancy between hypofractionation studies and many other literature reports about the incidence of breast fibrosis reported for standard fractionation. Breast fibrosis can be a potential side effect of hypofractionated radiotherapy that needs to be further studied.

\section{Additional Information \\ Disclosures}

Conflicts of interest: In compliance with the ICMJE uniform disclosure form, all authors declare the following: Payment/services info: All authors have declared that no financial support was received from any organization for the submitted work. Financial relationships: All authors have declared that they have no financial relationships at present or within the previous three years with any organizations that might have an interest in the submitted work. Other relationships: All authors have declared that there are no other relationships or activities that could appear to have influenced the submitted work.

\section{References}

1. Smith BD, Bellon JR, Blitzblau R, et al.: Radiation therapy for the whole breast: executive summary of an American Society of Radiation Oncology (ASTRO) evidence-based guideline. Pract Radiat Oncol. 2018, 8:145-152. 10.1016/j.prro.2018.01.012

2. START Trialists' Group, Bentzen SM, Agrawal RK, et al.: The UK standardization of breast radiotherapy (START) trial A of radiotherapy hypofractionation for treatment of early breast cancer: a randomized trial. Lancet Oncol. 2008, 9:331-341. 10.1016/S1470-2045(08)70077-9

3. START Trialists' Group, Bentzen SM, Agrawal RK, et al.: The UK standardization of breast radiotherapy (START) trial B of radiotherapy hypofractionation for treatment of early breast cancer: a randomized trial. Lancet. 2008, 371:1098-1107. 10.1016/S0140-6736(08)60348-7

4. Whelan TJ, Pignol JP, Levine MN, et al.: Long-term results of hypofractionated radiation therapy for breast 
cancer. N Engl J Med. 2010, 362:513-520. 10.1056/NEJMoa0906260

5. Whelan T, MacKenzie R, Julian J, et al.: Randomized trial of breast irradiation schedules after lumpectomy for women with lymph node-negative breast cancer. J Natl Cancer Inst. 2002, 94:1143-1150.

10.1093/jnci/94.15.1143

6. Yarnold J, Ashton A, Bliss J, et al.: Fractionation sensitivity and dose response of late adverse effects in the breast after radiotherapy for early breast cancer: long-term results of a randomised trial. Radiother Oncol. 2005, 75:9-17. 10.1016/j.radonc.2005.01.005

7. Hall E: Time, dose, and fractionation in radiotherapy. Radiobiology for the Radiologist. Lippincott Williams \& Wilkins, Philadelphia; 2012. 23:393-395.

8. Leong N, Truong PT, Tankel K, et al.: Hypofractionated nodal radiation therapy for breast cancer was not associated with increased patient-reported arm or brachial plexopathy symptoms. Int J Radiat Oncol Biol Phys. 2017, 99:1166-1172. 10.1016/j.ijrobp.2017.07.043

9. Reddy JP, Lei X, Huang SC, et al.: Quantitative assessment of breast cosmetic outcome after whole-breast irradiation. Int J Radiat Oncol Biol Phys. 2017, 97:894-902. 10.1016/j.ijrobp.2016.12.021

10. Haviland JS, Mannino M, Griffin C, Porta N, Sydenham M, Bliss JM, Yarnold JR: Late normal tissue effects in the arm and shoulder following lymphatic radiotherapy: Results from the UK START (standardization of breast radiotherapy) trials. Radiother Oncol. 2018, 126:155-162. 10.1016/j.radonc.2017.10.033

11. Yang X, Torres M, Henry S, et al.: Ultrasound tissue characterization of breast fibrosis following hypofractionated breast radiotherapy. Oncology (Williston Park). 2015, 29:204945.

12. Yu E, Huang D, Leonard K, et al.: Analysis of outcomes using hypofractionated tumor bed boost combined with hypofractionated whole breast irradiation for early-stage breast cancer. Clin Breast Cancer. 2017, 17:638-643. 10.1016/j.clbc.2017.05.010

13. Pezner RD: Cosmetic breast fibrosis: it's the local boost!. Int J Radiat Oncol Biol Phys. 1994, 30:1251-1252. 10.1016/0360-3016(94)90337-9

14. Bartelink H, Horiot JC, Poortmans PM, et al.: Impact of a higher radiation dose on local control and survival in breast-conserving therapy of early breast cancer: 10-year results of the randomized boost versus no boost EORTC 22881-10882 trial. J Clin Oncol. 2007, 25:3259-65. 10.1200/JCO.2007.11.4991

15. Murphy C, Anderson PR, Li T, et al.: Impact of the radiation boost on outcomes after breast-conserving surgery and radiation. Int J Radiat Oncol Biol Phys. 2011, 81:69-76. 10.1016/j.ijrobp.2010.04.067

16. Harris JR, Levene MB, Svensson G, Hellman S: Analysis of cosmetic results following primary radiation therapy for stages I and II carcinoma of the breast. Int J Radiat Oncol Biol Phys. 1979, 5:257-261. 10.1016/0360-3016(79)90729-6

17. De la Rochefordière A, Abner AL, Silver B, et al.: Are cosmetic results following conservative surgery and radiation therapy for early breast cancer dependent on technique?. Int J Radiat Oncol Biol Phys. 1992, 23:925-931. 10.1016/0360-3016(92)90896-P

18. The radiation fibrosis syndrome. Memorial Sloan-Kettering Cancer Center. 2013, Accessed: September 19, 2018: https://www.mskcc.org/sites/default/files/node/19501/documents/plenary-radiation-fibrosissyndrome-michael-stubblefie....

19. Boero IJ, Gillespie EF, Hou J, et al.: The impact of radiation oncologists on the early adoption of hypofractionated radiation therapy for early-stage breast cancer. Int J Radiat Oncol Biol Phys. 2017, 97:571580. 10.1016/j.ijrobp.2016.11.009 